\title{
Association between carotid diameter and the advanced glycation endproduct $\mathbf{N} \varepsilon_{-}$-Carboxymethyllysine (CML)
} Marcus Baumann*1, Tom Richart ${ }^{2,3}$, Daniel Sollinger ${ }^{1}$, Jaroslav Pelise ${ }^{4}$, Marcel Roos ${ }^{1}$, Tatiana Kouznetsova ${ }^{3}$, Hans-Henning Eckstein ${ }^{4}$, Uwe Heemann ${ }^{1}$ and Jan A Staessen ${ }^{2,3}$

\author{
Address: ${ }^{1}$ Department of Nephrology, Klinikum rechts der Isar, Technische Universität München, Munich, Germany, ${ }^{2}$ Genetic Epidemiology Unit, \\ Department of Epidemiology, Maastricht University, Maastricht, the Netherlands, ${ }^{3}$ Studies Coordinating Centre, Division of Hypertension and \\ Cardiac Rehabilitation, Department of Cardiovascular Diseases, University of Leuven, Leuven, Belgium and ${ }^{4}$ Department of Vascular Surgery, \\ Klinikum rechts der Isar, Technische Universität München, Munich, Germany \\ Email: Marcus Baumann* - marcus.baumann@Irz.tum.de; Tom Richart - tom.richart@med.kuleuven.be; \\ Daniel Sollinger - daniel.sollinger@Irz.tum.de; Jaroslav Pelisek - pelisek@gmx.de; Marcel Roos - marcel.roos@lrz.tum.de; \\ Tatiana Kouznetsova - Tatiana.Kouznetsova@med.kuleuven.be; Hans-Henning Eckstein - gefaesschirurgie@lrz.tu-muenchen.de; \\ Uwe Heemann - uwe.heeman@Irz.tum.de; Jan A Staessen - jan.staessen@med.kuleuven.be \\ * Corresponding author
}

Published: 6 August 2009

Cardiovascular Diabetology 2009, 8:45 doi:10.1 186/1475-2840-8-45

This article is available from: http://www.cardiab.com/content/8///45

(C) 2009 Baumann et al; licensee BioMed Central Ltd.

This is an Open Access article distributed under the terms of the Creative Commons Attribution License (http://creativecommons.org/licenses/by/2.0), which permits unrestricted use, distribution, and reproduction in any medium, provided the original work is properly cited.
Received: 8 June 2009

Accepted: 6 August 2009

\begin{abstract}
Background: $\mathrm{N}^{\varepsilon}$-Carboxymethyllysine $(\mathrm{CML})$ is the major non-cross linking advanced glycation end product (AGE). CML is elevated in diabetic patients and apparent in atherosclerotic lesions. AGEs are associated with hypertension and arterial stiffness potentially by qualitative changes of elastic fibers. We investigated whether CML affects carotid and aortic properties in normoglycemic subjects.

Methods: Hundred-two subjects (age $48.2 \pm 1 \mathrm{I} .3$ years) of the FLEMENGHO study were stratified according to the median of the plasma CML level $\left(200.8 \mathrm{ng} / \mathrm{ml} ; 25^{\text {th }}\right.$ percentile: $181.6 \mathrm{ng} / \mathrm{ml}$, $75^{\text {th }}$ percentile: 226. $\mathrm{ng} / \mathrm{ml}$ ) into "high CML" versus "low CML" as determined by ELISA. Local carotid artery properties, carotid intima media thickness (IMT), aortic pulse wave velocity (PWV), blood pressure and fetuin-A were analyzed. In 26 patients after carotidectomy, CML was visualized using immunohistochemistry.

Results: According to the CML median, groups were similar for anthropometric and biochemical data. Carotid diameter was enlarged in the "high" CML group $(485.7 \pm 122.2$ versus 42 I.2 \pm I $33.2 \mu \mathrm{m}$; $P<0.05)$, in particular in participants with elevated blood pressure and with "high" CML ("low" CML: $377.9 \pm 122.2$ $\mu \mathrm{m}$ and "high" CML: $514.5 \pm 151.6 \mu \mathrm{m} ; \mathrm{P}<0.00 \mathrm{I})$. CML was associated fetuin-A as marker of vascular inflammation in the whole cohort $(r=0.28 ; P<0.01)$ and with carotid diameter in hypertensive subjects $(r=0.42 ; P<0.0 I)$. CML level had no effect on aortic stiffness. CML was detected in the subendothelial space of human carotid arteries.

Conclusion: In normoglycemic subjects CML was associated with carotid diameter without adaptive changes of elastic properties and with fetuin-A as vascular inflammation marker, in particular in subjects with elevated blood pressure. This may suggest qualitative changes of elastic fibers resulting in a defective mechanotransduction, in particular as CML is present in human carotid arteries.
\end{abstract}




\section{Introduction}

The quality of elastic fibers reflects a hallmark of cardiovascular aging and can be affected by the deposition of interstitial collagen, calcification, lipid peroxidation and glycoxidation. The latter are induced by advanced glycation end products (AGEs) which are generated by nonenzymatic glycation and oxidation of protein and reducing sugars [1]. Their formation is increased in the blood and tissues of diabetic subjects as a result of hyperglycemia and is implicated in diabetes-associated vascular

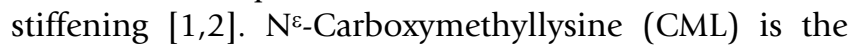
major non-cross linking AGE, which acts via the receptor of AGE (RAGE), thereby stimulating proinflammatory action [3]. In atherosclerotic lesions CML is present in infiltrating cells, suggesting a role of CML in the development of vascular lesions potentially by glycoxidation of elastin fibers [2].

Circulating levels of AGEs have been measured and related to the degree of coronary arteriosclerosis in both diabetic [4] and non-diabetic [5] patients with coronary artery disease and also to impaired left ventricular function in patients with type 1 diabetes. Recently McNulty et al. observed that the concentration of plasma AGEs is significantly higher in hypertensive than in normotensive subjects and related to aortic stiffness independent of age and blood pressure [6]. Therefore they suggested that plasma AGEs may play a blood pressure independent role in vascular remodeling in essential hypertension, in particular as vascular remodeling is associated with inflammation [7,8] which reflects a major action of AGEs [9]. However, latter results needed to be confirmed in a strict normoglycemic group and furthermore need to be extended to carotid artery properties. Based on these observations we studied the relationship between plasma $\mathrm{CML}$, carotid and aortic properties, in normoglycemic subjects. To investigate in how far CML is associated with vascular inflammatory processes fetuin-A was investigated as biomarker for vascular inflammation [10,11]. In this context we furthermore investigated whether fetuin-A explains carotid diameter changes. Additionally, we investigated the presence of CML in carotid arteries with atherosclerotic lesions to link systemic measures with local function and local CML deposition.

\section{Methods}

Hundred-two subjects of the FLEMish study of ENvironment, Genes and Health Outcomes (FLEMENGHO) [12] involving a random sample of families living in a defined geographical area in northern Belgium were included in this study. The Ethics Committee of the University of Leuven and Munich approved the study, respectively. All participants gave informed written consent. The inclusion criteria for the Flemish cohort were participation in a prospective substudy, the age of at least 18 years, no antihy- pertensive or antihypertensive treatment and normoglycemia defined as fasting blood sugar below 6.7 $\mathrm{mmol} / \mathrm{l}$. The inclusion criteria for the immunohistochemistry were atheromatous alteration of the carotid artery in context with the clinical need of carotidectomy.

For at least $3 \mathrm{~h}$ before being examined, the participants refrained from heavy exercise, smoking, alcohol or caffeine-containing beverages. Trained nurses measured blood pressure and anthropometric characteristics. They administered a questionnaire to collect information about each subject's medical history, smoking and drinking habits, and intake of medications. Each participant's office blood pressure was the average of five consecutive readings. Elevated blood pressure was a systolic blood pressure above $140 \mathrm{mmHg}$ and/or $90 \mathrm{mmHg}$ diastolic or use of antihypertensive treatment. Body mass index (BMI) was weight in kilograms divided by the square of height in metres. $\mathrm{N}^{\varepsilon}$-Carboxymethyllysine $(\mathrm{CML})$ plasma level of free CML and protein-bound CML was measured using an ELISA kit (Microcoat, Bernried, Germany), following the instructions of the manufacturer. Intra- and interassay variability were below 5\%. The entire cohort was grouped according to the median of plasma CML (median: 200.8, $25^{\text {th }}$ percentile: $181.6,75^{\text {th }}$ percentile: 226.1 ). The values below median are referred to as "low" and these above median as "high" CML, respectively. Blood glucose, total cholesterol, HDL, LDL, triglycerides, and serum creatinine were also measured in all subjects by routine laboratory methods. Fetuin-A was measured by commercially available ELISA according to the manufacturer protocol [13].

By means of a pulsed ultrasound wall-tracking system (Wall Track System; Pie Medical, Maastricht, The Netherlands), 3 trained researchers obtained vascular measurements at the common carotid artery $2 \mathrm{~cm}$ proximal of the carotid bulb. During the ultrasound examination, an automated oscillometric device (Dinamap 845; Critikon Inc, Tampa, FL, USA) recorded blood pressure at the upper arm at 5-minute intervals. As for the conventional auscultatory measurements, cuff size was adjusted to the circumference of the upper arm. Standard cuffs had an inflatable bladder of $12 \times 24 \mathrm{~cm}$ [14]. As described elsewhere, the observers used applanation tonometry with a pencil-shaped probe (Millar Instruments Inc, Houston, TX, USA) and calibration to mean arterial pressure and diastolic blood pressure at the brachial artery to derive the local pulse pressure at the carotid artery. We computed cross-sectional compliance (CC) and the distensibility coefficient (DC) from the diastolic cross-sectional area $(\mathrm{A})$, the systolic increase in cross-sectional area $(\Delta \mathrm{A})$, and the local pulse pressure (PP): $\mathrm{CC}=\Delta \mathrm{A} / \mathrm{PP}$ and $\mathrm{DC}=(\Delta \mathrm{A} /$ $\mathrm{A}) / \mathrm{PP}$. A and $\Delta \mathrm{A}$ were calculated from diameter (D) and the change in diameter $(\Delta D)$ as $A=\pi\left(\Delta(D / 2)^{2}\right.$ and $\Delta A=\pi \mathrm{X}[(\mathrm{D}+\Delta \mathrm{D}) / 2)^{2}-\pi \mathrm{X}(\mathrm{D} / 2)$, respectively. The intraob- 
server intrasession variability was $<10 \%$ for the carotid measurements. The intraobserver intersession and interobserver intrasession variability were of the same order of magnitude.

The observers also determined carotid-femoral pulse wave velocity (PWV) from the length of the carotid-femoral segment and the transit time of the pulse wave. The carotidfemoral segment was the difference of the distances between the site of the carotid ultrasound measurement and the suprasternal notch and between the suprasternal notch and the site of the femoral measurement. We measured PWV using a high-fidelity SPC-301 micromanometer (Millar Instruments, Inc.) interfaced with a laptop computer running the SphygmoCor software, version 6.31 (AtCor Medical Pty Ltd, Sydney, Australia).

Immunohistochemical CML staining of a carotid artery with atherosclerotic lesions was performed in human material after carotidectomy [15]. Twenty six paraformaldehyde-fixed, paraffin-embedded tissue sections were cut $(4 \mu \mathrm{m})$, dewaxed and rehydrated. After endogenous peroxidase blocking (endogenous enzyme block, Dakocytomation, Glostrup, Denmark), slides were incubated with a 1:100 dilution of CML biotine $0.34 \mathrm{mg} / \mathrm{ml}$ antibody, which was a kind gift by Dr. C. Schalkwijk (University Maastricht). This was followed by incubation with a 1:400 diluted secondary rabbit anti- mouse IgG HRP antibody (Serotec, Wiesbaden, Germany) and developed in diaminobenzidine tetrahydrochloride (DAB substrate kit for peroxidase SK-4100; Vector Laboratories, Burlingame, CA, USA) and counterstained with hematoxylin.
Statistical analyses were performed using SPSS software version 15.0 (SPSS, Chicago, IL, USA). Comparison between subjects with above and below the median of CML was performed by unpaired t-test or the $\chi^{2}$-test. The Spearman correlation coefficient was assessed for CML and the clinical properties in the whole cohort and the subgroup of normotensive and hypertensive subjects. Results are expressed as mean $\pm \mathrm{SD}$. A p value of less than 0.05 was considered to be statistically significant.

\section{Results}

Baseline characteristics of the Flemish cohort and according to the median plasma CML level of the cohort (median: $200.8,25^{\text {th }}$ percentile: $181.6,75^{\text {th }}$ percentile: 226.1) are given in Table 1. Apart from plasma CML values no significant difference was present between the "low" and "high" CML group, in particular no differences in fasting blood glucose and lipid profile. Thirty-three subjects had elevated blood pressure level, including 20 with "low" CML and 13 with "high" CML.

Arterial properties according to the total cohort and according to the median plasma CML level of the cohort are given in Table 2. Carotid diameter was significantly larger in the "high" CML group $(P<0.05)$. PWV was not different between the "low" and "high" CML group. The bivariate Spearman association of CML and carotid diameter is for the normotensive cohort $\mathrm{r}=-0.01(\mathrm{P}=0.92)$ and for subjects with elevated blood pressure $\mathrm{r}=0.42(\mathrm{P}<$ 0.01 ; Table 3 and Figure 1). Additionally, the role of vascular inflammation was investigated with fetuin-A. CML is positively associated with fetuin-A $(\mathrm{r}=0.28 ; \mathrm{P}<0.01)$.

Table I: Baseline Characteristics according to $\mathrm{CML}(\mathrm{n}=102$, mean \pm SD)

\begin{tabular}{|c|c|c|c|}
\hline Characteristic & All & $\begin{array}{c}C M L \leq \text { Median } \\
(n=5 I)\end{array}$ & $\begin{array}{c}\text { CML>Median } \\
(n=51)\end{array}$ \\
\hline Age $(y)$ & $48.2 \pm 11.3$ & $50.2 \pm 11.7$ & $46.8 \pm 10.7$ \\
\hline Male, female & $53 / 49$ & $26 / 25$ & $27 / 24$ \\
\hline $\mathrm{BMI}\left(\mathrm{kg} / \mathrm{m}^{2}\right)$ & $25.8 \pm 3.7$ & $25.8 \pm 3.7$ & $25.8 \pm 3.6$ \\
\hline Smoking status & $71 / 31$ & $36 / 15$ & $35 / 16$ \\
\hline \multicolumn{4}{|l|}{ (nonsmokers/smokers) } \\
\hline Brachial SBP (mmHg) & $128.4 \pm 14.9$ & $128.1 \pm 13.2$ & $129.0 \pm 16.9$ \\
\hline Brachial DBP $(\mathrm{mmHg})$ & $82.7 \pm 10.5$ & $83.1 \pm 9.3$ & $82.4 \pm 12.0$ \\
\hline Brachial PP $(\mathrm{mmHg})$ & $45.8 \pm 10.2$ & $45.0 \pm 10.0$ & $46.6 \pm 10.2$ \\
\hline Cholesterol (mmol/L) & $5.6 \pm 1.0$ & $5.5 \pm 1.0$ & $5.8 \pm 0.9$ \\
\hline $\mathrm{HDL}(\mathrm{mmol} / \mathrm{L})$ & $1.4 \pm 0.3$ & $1.3 \pm 0.3$ & $1.4 \pm 0.3$ \\
\hline LDL (mmol/L) & $3.4 \pm 0.9$ & $3.3 \pm 0.9$ & $3.6 \pm 0.9$ \\
\hline Triglycerides (mmol/L) & $2.5 \pm 1.4$ & $2.6 \pm 1.6$ & $2.2 \pm 1.0$ \\
\hline Glucose (mmol/L) & $5.0 \pm 0.7$ & $4.9 \pm 0.7$ & $5.0 \pm 0.8$ \\
\hline Creatinine $(\mu \mathrm{mol} / \mathrm{L})$ & $92.0 \pm 17.1$ & $93.0 \pm 16.0$ & $92.3 \pm 17.8$ \\
\hline Fetuin $(\mu \mathrm{g} / \mathrm{ml})$ & $108.7 \pm 52.3$ & $100.8 \pm 48.8$ & $115.9 \pm 55.2$ \\
\hline CML (ng/ml) & $210.4 \pm 43.7$ & $183.0 \pm|2|$. & $240.7 \pm 46.1$ \\
\hline
\end{tabular}

CML median: $200.8 \mathrm{ng} / \mathrm{ml}$, Student's t-test and Mann-Whitney-U test where appropriate Bold: $\mathbf{P}<\mathbf{0 . 0 5}$

CML: $N^{\varepsilon}$ Carboxymethyllysine, BMl: body mass index, SBP: systolic blood pressure, DBP: diastolic blood pressure, PP: pulse pressure. 
A

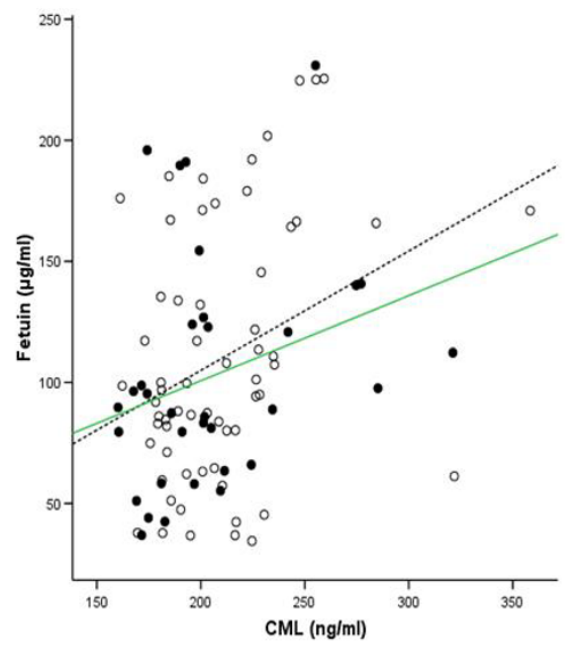

B

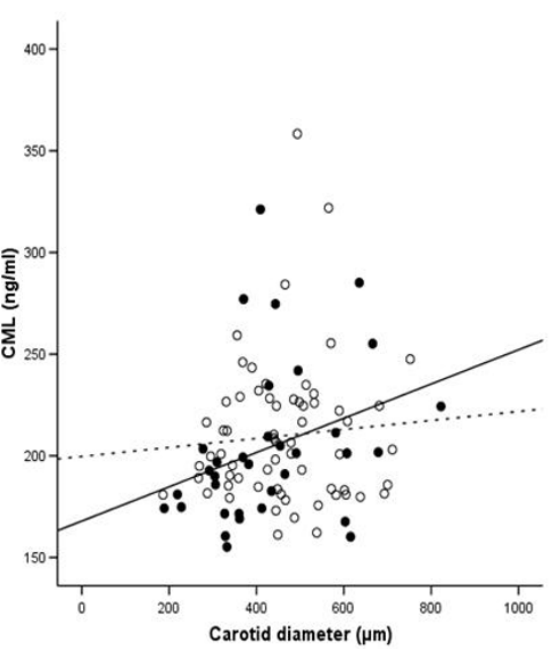

C

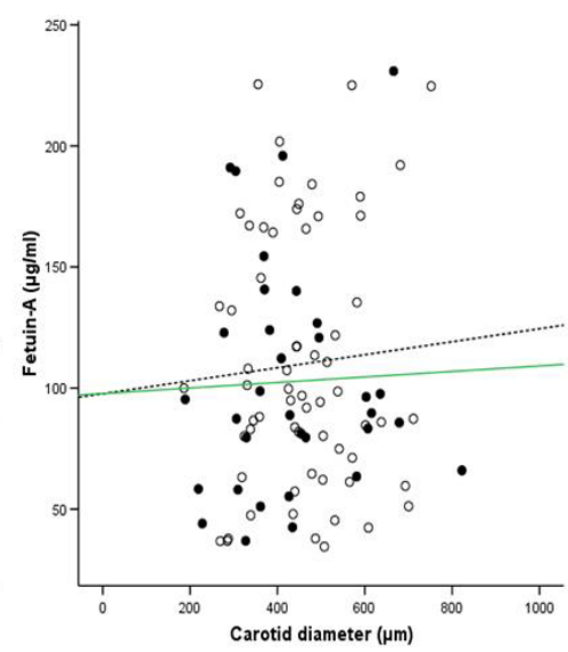

\section{Figure I}

Association between CML, Fetuin-A and carotid diameter. CML and Fetuin-A are positively associated in hypertensive (open square) and normotensive (filled black square) subjects $(A ; r=0.34$ and $r=0.27$, respectively). $B$ demonstrates that $C M L$ is associated with carotid diameter restricted to hypertensive subjects $(r=0.42)$. $C$ demonstrates that fetuin-A is not associated with carotid diameter. All correlations are given as calculated by Spearman correlation coefficient. Continuous lines indicate the regression of data represented by open circles and dotted lines those of closed circles.

However Fetuin-A is in not associated with carotid diameter in any group (Figure 1).

Comparing subjects with normal and elevated blood pressure, no difference was apparent with respect to CML and carotid diameter. However, PWV was significantly elevated in the group with elevated blood pressure $(6.5 \pm 2.1$ versus $7.5 \pm 2.4 \mathrm{~m} / \mathrm{s} ; \mathrm{P}<0.05$; Table 4 ).

Subdividing the normotensive subjects according to the CML median no significant differences were apparent for carotid and aortic properties (data not shown). In contrast, subdividing the group with elevated blood pressure according to the CML median resulted in an increased carotid diameter in the 13 subjects with "high" CML $(514.5 \pm 151.6 \mu \mathrm{m})$ as compared to the 20 subjects with "low" CML (377.9 $\pm 122.2 \mu \mathrm{m}, \mathrm{P}<0.001$; Figure 2), while the elastic properties as cross-sectional compliance ("high" CML: $0.94 \pm 0.33$ versus "low" CML: $0.72 \pm 0.29$ $\mathrm{mm}^{2} / \mathrm{kPa} ; \mathrm{P}=0.07$ ) and distensibility ("high" CML: 21.2 \pm 7.1 versus "low" CML: $18.0 \pm 7.310^{-3} / \mathrm{kPa}$; $\mathrm{P}=0.20$ ) were comparable between these two subgroups.

The characteristics of the patients with carotidectomy are summarized in Table 5. Immunohistochemical staining of CML in the human carotid artery is shown in Figure 3. The magnification of $2 \mathrm{~A}(100 \times)$ and $2 \mathrm{~B}(400 \times)$ reveal CML positive cells in the subendothelial space. CML stain-

Table 2: Arterial characteristics $(n=102$, mean \pm SD)

\begin{tabular}{|c|c|c|c|}
\hline Characteristics & All & $\begin{array}{c}C M L \leq \text { Median } \\
(n=5 I)\end{array}$ & $\begin{array}{c}\text { CML>Median } \\
(n=5 I)\end{array}$ \\
\hline PWV (m/s) & $6.8 \pm 2.2$ & $7.2 \pm 2.6$ & $6.5 \pm 1.7$ \\
\hline \multicolumn{4}{|l|}{ Common carotid artery } \\
\hline IMT & $0.82 \pm 0.17$ & $0.82 \pm 0.17$ & $0.81 \pm 0.18$ \\
\hline Diameter, $\mu \mathrm{m}$ & $449.0 \pm 130.7$ & $421.2 \pm 133.2$ & $485.7 \pm 122.2$ \\
\hline Pulse pressure, $\mathrm{mm} \mathrm{Hg}$ & $45.0 \pm 8.9$ & $44.8 \pm 9.2$ & $45.6 \pm 8.7$ \\
\hline $\mathrm{CC}, \mathrm{mm}^{2} / \mathrm{kPa}$ & $0.91 \pm 0.33$ & $0.85 \pm 0.32$ & $0.98 \pm 0.34$ \\
\hline $\mathrm{DC}, 10^{-3} / \mathrm{kPa}$ & $22.5 \pm 8.4$ & $21.4 \pm 8.8$ & $23.7 \pm 8.0$ \\
\hline
\end{tabular}

CML median: $200.8 \mathrm{ng} / \mathrm{ml}$, Student's t-test and Mann-Whitney-U test where appropriate Bold: $\mathbf{P}<\mathbf{0 . 0 5}$

CML: $N^{\varepsilon}$ Carboxymethyllysine, PWV: pulse wave velocity, IMT: intima media thickness, CC: cross-sectional compliance, DC: distensibility coefficient 
Table 3: Association between CML and clinical characteristics of the whole cohort, normotensive and hypertensive subjects

\begin{tabular}{|c|c|c|c|c|c|c|}
\hline & \multicolumn{2}{|c|}{ Total cohort } & \multicolumn{2}{|c|}{ Normotension } & \multicolumn{2}{|c|}{ Hypertension } \\
\hline & $r$ & $P$ value & $r$ & $P$ value & $r$ & $P$ value \\
\hline Age & -0.17 & 0.10 & -0.13 & 0.29 & -0.17 & 0.34 \\
\hline Sex & -0.04 & 0.76 & -0.15 & 0.24 & 0.19 & 0.30 \\
\hline BMI & 0.05 & 0.60 & 0.01 & 0.99 & 0.17 & 0.33 \\
\hline Smoking & 0.03 & 0.75 & -0.02 & 0.88 & 0.05 & 0.78 \\
\hline SBP & 0.02 & 0.81 & 0.09 & 0.46 & 0.30 & 0.09 \\
\hline DBP & -0.05 & 0.58 & -0.04 & 0.73 & 0.17 & 0.34 \\
\hline PP & 0.12 & 0.22 & 0.14 & 0.26 & 0.16 & 0.37 \\
\hline Creatinine & -0.10 & 0.37 & -0.03 & 0.82 & -0.11 & 0.54 \\
\hline Glucose & 0.05 & 0.61 & -0.08 & 0.55 & 0.13 & 0.46 \\
\hline Cholesterol & 0.20 & 0.05 & 0.23 & 0.06 & 0.15 & 0.40 \\
\hline HDL & 0.17 & 0.08 & 0.08 & 0.53 & 0.31 & 0.07 \\
\hline LDL & 0.21 & 0.04 & 0.27 & 0.03 & 0.15 & 0.41 \\
\hline Triglycerides & -0.07 & 0.52 & -0.04 & 0.71 & -0.09 & 0.63 \\
\hline Fetuin & 0.28 & 0.01 & 0.27 & 0.03 & 0.34 & 0.04 \\
\hline PWV & -0.12 & 0.23 & -0.20 & 0.10 & 0.06 & 0.75 \\
\hline \multicolumn{7}{|c|}{ Common carotid artery } \\
\hline IMT & 0.08 & 0.45 & 0.15 & 0.25 & -0.06 & 0.72 \\
\hline Diameter & 0.18 & 0.07 & -0.01 & 0.93 & 0.42 & 0.01 \\
\hline Pulse pressure & 0.10 & 0.34 & 0.09 & 0.48 & 0.18 & 0.31 \\
\hline CC & 0.12 & 0.26 & -0.07 & 0.56 & 0.26 & 0.14 \\
\hline DC & 0.11 & 0.30 & 0.01 & 0.99 & 0.21 & 0.23 \\
\hline
\end{tabular}

Spearman correlation coefficient Bold: $\mathbf{P}<\mathbf{0 . 0 5}$

CML: N₹Carboxymethyllysine, BMI: body mass index, SBP: systolic blood pressure, DBP: diastolic blood pressure, PP: pulse pressure, PWV: pulse wave velocity, IMT: intima media thickness, CC: cross-sectional compliance, DC: distensibility coefficient

ing is present in atheromatous lesions and colocalizes with inflammatory cells.

\section{Discussion}

The main finding of this study is that carotid enlargement is apparent in context with elevated CML plasma levels which are still in the normal range. Moreover, the effect of CML on carotid enlargement is predominantly present in subjects with elevated blood pressure without changes in cross-sectional compliance or distensibility. Finally, CML was associated with fetuin-A as vasculo-inflammatory marker and was present in the subendothelial space of human carotid arteries.

CML is involved in vascular stiffening of type 1 diabetics as well as of hypertensive subjects $[6,16]$. Our study demonstrates that carotid enlargement is apparent in this cohort of normoglycemic subjects. This is particularly striking in subjects with hypertensive blood pressure values, where CML demonstrated an independent association with carotid diameter. Moreover, the shown effect is already present at a CML range below levels obtained in diabetes or renal insufficiency $[17,18]$.

Although no prospective data exist on carotid diameter, Kawamoto et al. showed that the carotid artery diameter correlates with conventional cardiovascular risk factors including alcohol consumption [19], these findings sug- gest that the carotid artery diameter may reflect the ability of adaptive remodeling to the atherosclerosis before plaque formation. Moreover, increased carotid artery diameter as consequence of arterial stiffness limits the deterioration of the buffering capacity of the central artery [20]. Thus, CML can be an important factor during the development of atherosclerosis and may be relevant in clinical risk assessment. As atherosclerosis is driven by inflammation, we additionally assessed fetuin- $A$ as marker for vascular inflammation $[21,22]$. In this context, we observed and association between fetuin-A and CML throughout the whole cohort. This suggests that $\mathrm{CML}$ potentially reflects the state of vascular inflammation [23]. This is further strengthened by our observation of $\mathrm{CML}$ in the subendothelial space of atherosclerotic human carotid artery material which is in line with previous descriptions in human aortic valves [24].

The mechanisms underlying this CML-related effect on carotid diameter cannot primarily be explained by an enhanced cross linking by AGEs as CML may affect the properties of the AGE-modified proteins but does not cause cross-linking in or between proteins $[25,26]$. Therefore, our findings suggest that the effect of CML on arterial diameter involves mechanisms other than cross-linking, such as ligation of the receptor for AGE (RAGE) [27]. RAGE is highly expressed in the endothelium of activated vessels [28]. Furthermore, CML is a ligand for RAGE [29]. 
Table 4: Baseline Characteristics according to blood pressure (n $=(02$, mean \pm SD)

\begin{tabular}{|c|c|c|}
\hline Characteristic & $\begin{array}{c}\text { Normal BP } \\
(n=69)\end{array}$ & $\begin{array}{l}\text { Elevated BP } \\
\quad(n=33)\end{array}$ \\
\hline Age $(y)$ & $47.0 \pm 10.5$ & $50.6 \pm 12.7$ \\
\hline Male, female & $36 / 33$ & $17 / 16$ \\
\hline BMI $\left(\mathrm{kg} / \mathrm{m}^{2}\right)$ & $25.5 \pm 3.5$ & $26.3 \pm 3.9$ \\
\hline Non-Smokers/Smokers & $49 / 20$ & $22 / 11$ \\
\hline Brachial SBP (mmHg) & $|2| .5 \pm 8.7$ & $142.2 \pm 15.0$ \\
\hline Brachial DBP (mmHg) & $78.1 \pm 6.9$ & $92.0 \pm 10.5$ \\
\hline Cholesterol (mmol/L) & $5.6 \pm 1.0$ & $5.6 \pm 0.9$ \\
\hline $\mathrm{HDL}(\mathrm{mmol} / \mathrm{L})$ & $1.4 \pm 0.4$ & $1.4 \pm 0.3$ \\
\hline LDL (mmol/L) & $3.4 \pm 0.9$ & $3.4 \pm 0.9$ \\
\hline Triglycerides (mmol/L) & $2.4 \pm 1.2$ & $2.5 \pm 1.6$ \\
\hline Glucose (mmol/L) & $5.0 \pm 0.7$ & $4.8 \pm 0.8$ \\
\hline Creatinine $(\mu \mathrm{mol} / \mathrm{L})$ & $91.6 \pm 15.8$ & $91.6 \pm 15.2$ \\
\hline Fetuin $(\mu \mathrm{g} / \mathrm{ml})$ & $110.0 \pm 53.2$ & $106.1 \pm 51.4$ \\
\hline CML (ng/ml) & $2 \mid 4.2 \pm 46.6$ & $209.3 \pm 40.7$ \\
\hline $\mathrm{PWV}(\mathrm{m} / \mathrm{s})$ & $6.5 \pm 2.1$ & $7.5 \pm 2.4$ \\
\hline \multicolumn{3}{|l|}{ Common carotid artery } \\
\hline IMT & $0.81 \pm 0.16$ & $0.84 \pm 0.19$ \\
\hline Diameter, $\mu \mathrm{m}$ & $458.5 \pm 121.1$ & $430.1 \pm 148.1$ \\
\hline Pulse pressure, $\mathrm{mm} \mathrm{Hg}$ & $42.9 \pm 7.7$ & $49.2 \pm 9.8$ \\
\hline $\mathrm{CC}, \mathrm{mm}^{2} / \mathrm{kPa}$ & $0.96 \pm 0.32$ & $0.80 \pm 0.32$ \\
\hline $\mathrm{DC}, 10^{-3} / \mathrm{kPa}$ & $24.0 \pm 8.5$ & $19.2 \pm 7.3$ \\
\hline
\end{tabular}

Student's t-test and Mann-Whitney-U test where appropriate Bold: $\boldsymbol{P}$ $<0.05, C M L$ : N ${ }^{\varepsilon}$ Carboxymethyllysine, BMI: body mass index, SBP: systolic blood pressure, DBP: diastolic blood pressure, PWV: pulse wave velocity, IMT: intima media thickness, CC: cross-sectional compliance, DC: distensibility coefficient

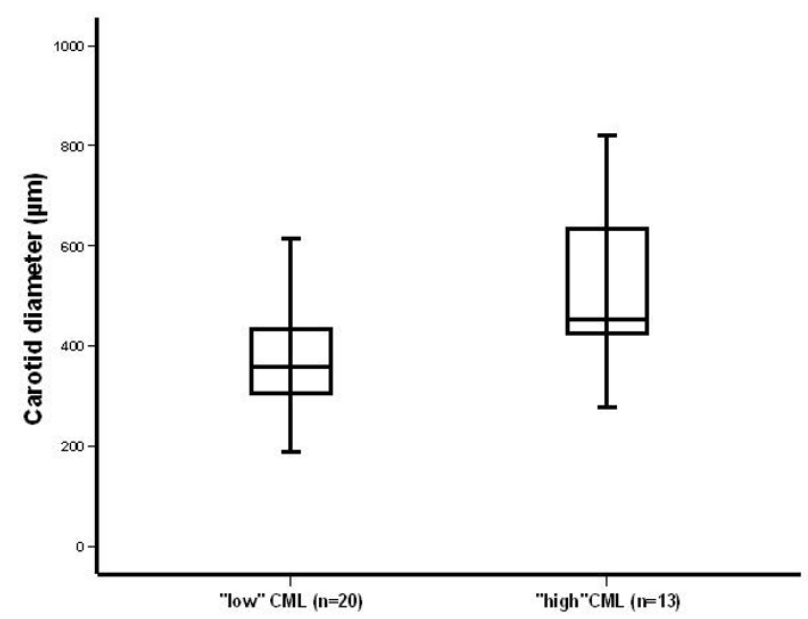

\section{Figure 2}

Carotid diameter in subjects with elevated blood pressure $(n=33)$ according to the $C M L$ median. Carotid diameter was significantly lower in 20 subjects with "low" CML (377.9 $\pm 122.1 \mu \mathrm{m})$ as compared to the I 3 subjects with "high" CML (5I4.5 \pm I5I.7 $\mu \mathrm{m} ; \mathrm{P}<0.00 \mathrm{I})$.

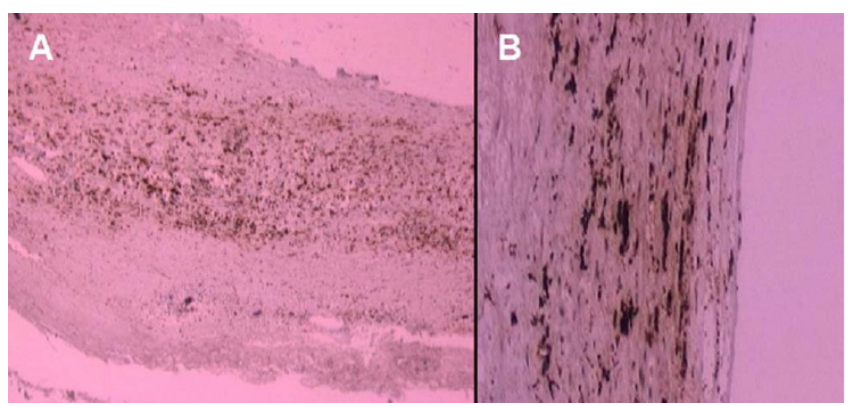

Figure 3

Representative immunohistochemical staining of CML in the human carotid artery. The magnification of 2A (100x) and 2B (400x) reveal CML positive cells in the subendothelial space.

Binding of circulating CML modified proteins to RAGE activates extracellular-regulated kinase $1 / 2$ (ERK1/2), nuclear factor $\kappa-\mathrm{B}$, secretion of proinflammatory cytokines, and modulates gene expression in several cell types, such as monocytes, endothelial cells, and vascular smooth muscle cells [30]. This may lead to changes in the production of extracellular matrix proteins, such as collagen and elastin structure, and alterations in vascular elasticity $[31,32]$, as obtained by glycoxidation, and lipid peroxidation [24]. Because CML can be formed by glycoxidation and lipid peroxidation [2], the association of carotid diameter with CML may reflect the involvement of increased oxidative stress in arterial remodelling [33] which is further strengthened by the association with fetuin-A. However, as the serum concentration of soluble RAGE is in the picomolar range [34] whereas the CML molaritiy is in the micromolar range, it is questionable that sRAGE/CML binding occurs in vivo and has any biological effect. In this respect, serum CML is more likely an

Table 5: Characteristics of patients with carotidectomy

\begin{tabular}{lc}
\hline Characteristic & Carotidectomy $(\mathbf{n}=\mathbf{2 6})$ \\
\hline Age $(\mathbf{y})$ & $73.0 \pm 8.4$ \\
Male, female & $18 / 8$ \\
BMI $\left(\mathrm{kg} / \mathrm{m}^{2}\right)$ & $26.6 \pm 4.5$ \\
Smokers $/$ Non-smokers & $10 / 16$ \\
Brachial SBP $(\mathrm{mmHg})$ & $139.4 \pm 14.3$ \\
Brachial DBP $(\mathrm{mmHg})$ & $77.4 \pm 6.3$ \\
No. Antihypertensives & $2.3 \pm 0.9$ \\
Hyperlipidemia $(\%)$ & 77 \\
Statin $(\mathrm{y} / \mathrm{n})$ & $21 / 5$ \\
Diabetes $(\%)$ & 46 \\
Insulin $(\mathbf{y} / \mathrm{n})$ & $7 / 19$ \\
eGFR $(\mathrm{ml} / \mathrm{min})$ & $65.3 \pm 22.1$ \\
Present CVD $(\mathrm{y} / \mathrm{n})$ & $6 / 20$ \\
CRP & $0.65 \pm 0.48$
\end{tabular}


indicator of a dysfunctional cellular metabolism in the vascular wall in particular as we demonstrated CML deposition in atheromatous lesions of the carotid artery.

CML had no effect on carotid enlargement in subjects with normotensive blood pressure values. By contrast, in subjects with elevated blood pressure the CML plasma level characterized the extent of carotid enlargement without adaptive changes of the elastic artery properties. This may in turn lead to increased circumferential wall stress and consecutively result in a potentially defective mechanotransduction, that is, the control of smooth muscle cell growth and migration, and production of extracellular matrix in response to diameter enlargement [35]. Furthermore, a direct effect on elastin may be considered as CML co-localizes with elastin [36] and results in fenestration of elastic laminae [37].

In this cohort no effect of CML on PWV was observed. Therefore this study contrasts a recent observation describing CML as blood pressure independent factor in aortic stiffness [6]. However, there are important differences between both studies. Firstly, in the latter study AGE measurement was performed using a non-selective ELISA detecting other AGEs than CML as well, while in our study a specific ELISA for CML was used [38]. Secondly, blood glucose levels were elevated in the hypertensive group of McNulty et al., suggesting a more general glucose effect on both CML level and stiffness complicating the detection of the effects of AGEs alone. By contrast, our study excluded subjects with a fasting blood sugar of $>6.7 \mathrm{mmol} / \mathrm{l}$.

In summary, normoglycemic subjects with higher CML plasma levels are characterized by carotid enlargement without changes in elastic properties, in particular in elevated blood pressure. This may be associated with a qualitative change of elastic fibers and may lead to a defective mechanotransduction both explainable by local glycoxidation and lipid peroxidation induced inflammation.

\section{Competing interests}

The authors declare that they have no competing interests.

\section{Authors' contributions}

$\mathrm{MB}$ designed, coordinated and wrote the manuscript. TR, TK and JS generated the data of the Flemish cohort. JP and HE provided the human carotid arteries. DS and UH coordinated and wrote the manuscript. All authors read and approved the final manuscript.

\section{References}

I. Bierhaus A, Chevion S, Chevion M, Hofmann M, Quehenberger P, Illmer T, Luther T, Berentshtein E, Tritschler H, Muller M, et al.: Advanced glycation end product-induced activation of NFkappaB is suppressed by alpha-lipoic acid in cultured endothelial cells. Diabetes 1997, 46(9): I48I-I490.
2. Schleicher E, Weigert $C$, Rohrbach $H$, Nerlich A, Bachmeier B, Friess $U$ : Role of glucoxidation and lipid oxidation in the development of atherosclerosis. Ann N Y Acad Sci 2005, 1043:343-354.

3. Schalkwijk CG, Baidoshvili A, Stehouwer CD, van Hinsbergh VW, Niessen HW: Increased accumulation of the glycoxidation product Nepsilon-(carboxymethyl)lysine in hearts of diabetic patients: generation and characterisation of a monoclonal anti-CML antibody. Biochim Biophys Acta 2004, 1636(23):82-89.

4. Kiuchi K, Nejima J, Takano T, Ohta M, Hashimoto H: Increased serum concentrations of advanced glycation end products: $a$ marker of coronary artery disease activity in type 2 diabetic patients. Heart (British Cardiac Society) 200I, 85(I):87-9I.

5. Kanauchi M, Tsujimoto N, Hashimoto T: Advanced glycation end products in nondiabetic patients with coronary artery disease. Diabetes Care 200I, 24(9):1620-1623.

6. McNulty M, Mahmud A, Feely J: Advanced glycation end-products and arterial stiffness in hypertension. Am J Hypertens 2007, 20(3):242-247.

7. Maki-Petaja KM, Hall FC, Booth AD, Wallace SM, Yasmin, Bearcroft PW, Harish S, Furlong A, McEniery CM, Brown J, et al.: Rheumatoid arthritis is associated with increased aortic pulse-wave velocity, which is reduced by anti-tumor necrosis factoralpha therapy. Circulation 2006, I I 4(I I): I I85-II 92.

8. Zhang H, Park Y, Wu J, Chen X, Lee S, Yang J, Dellsperger KC, Zhang C: Role of TNF-alpha in vascular dysfunction. Clin Sci (Lond) 2009, II 6(3):219-230.

9. Kneyber MC, Gazendam RP, Niessen HW, Kuiper JW, Dos Santos $\mathrm{CC}$, Slutsky AS, Plotz FB: Mechanical ventilation during experimental sepsis increases deposition of advanced glycation end products and myocardial inflammation. Critical care (London, England) 2009, I3(3):R87.

10. Ketteler M, Bongartz $P$, Westenfeld R, Wildberger JE, Mahnken AH, Bohm R, Metzger T, Wanner C, Jahnen-Dechent W, Floege J: Association of low fetuin-A (AHSG) concentrations in serum with cardiovascular mortality in patients on dialysis: a cross-sectional study. Lancet 2003, 36 I(9360):827-833.

II. Hennige AM, Staiger H, Wicke C, Machicao F, Fritsche A, Haring HU, Stefan N: Fetuin-A induces cytokine expression and suppresses adiponectin production. PLOS ONE 2008, 3(3): el 765.

12. Zhang H, Thijs L, Kuznetsova T, Fagard RH, Li X, Staessen JA: Progression to hypertension in the non-hypertensive participants in the Flemish Study on Environment, Genes and Health Outcomes. J Hypertens 2006, 24(9):1719-1727.

13. Roos M, Richart T, Kouznetsova T, von Eynatten M, Lutz J, Heemann $U$, Baumann M, Staessen JA: Fetuin-A and arterial stiffness in patients with normal kidney function. Regul Pept 2009, 10;1 54(13):39-43.

14. Seidlerova J, Staessen JA, Maillard M, Nawrot T, Zhang H, Bochud M, Kuznetsova T, Richart T, Van Bortel LM, Struijker-Boudier HA, et al: Association between arterial properties and renal sodium handling in a general population. Hypertension 2006, 48(4):609-6I5.

15. Baumann M, Caron M, Schmaderer C, Schulte C, Viklicky O, von Weyhern CW, Lutz J, Heemann U: Renal N(epsilon)-carboxymethyllysine deposition after kidney transplantation. Transplantation 2008, 86(2):330-335.

16. Schram MT, Schalkwijk CG, Bootsma AH, Fuller JH, Chaturvedi N, Stehouwer CD: Advanced glycation end products are associated with pulse pressure in type I diabetes: the EURODIAB Prospective Complications Study. Hypertension 2005, 46(1):232-237.

17. Wautier MP, Massin P, Guillausseau PJ, Huijberts M, Levy B, Boulanger E, Laloi-Michelin M, Wautier JL: N(carboxymethyl)lysine as a biomarker for microvascular complications in type 2 diabetic patients. Diabetes \& metabolism 2003, 29(I):44-52.

18. Busch M, Franke S, Wolf G, Brandstadt A, Ott U, Gerth J, Hunsicker LG, Stein G: The advanced glycation end product $\mathbf{N}$ (epsilon)carboxymethyllysine is not a predictor of cardiovascular events and renal outcomes in patients with type 2 diabetic kidney disease and hypertension. Am J Kidney Dis 2006, 48(4):57I-579.

19. Kawamoto R, Ohtsuka N, Kusunoki T, Yorimitsu N: An association between the estimated glomerular filtration rate and carotid atherosclerosis. Internal medicine (Tokyo, Japan) 2008, 47(5):39I-398. 
20. Sugawara J, Otsuki T, Maeda S, Tanabe T, Kuno S, Ajisaka R, Matsuda $M$ : Effect of arterial lumen enlargement on carotid arterial compliance in normotensive postmenopausal women. Hypertens Res 2005, 28(4):323-329.

21. Mori K, Emoto M, Araki T, Yokoyama H, Teramura M, Lee E, Motoyama K, Koyama H, Shoji T, Inaba M, et al.: Association of serum fetuin-A with carotid arterial stiffness. Clinical endocrinology 2007, 66(2):246-250.

22. Stenvinkel P, Wang K, Qureshi AR, Axelsson J, Pecoits-Filho R, Gao $P$, Barany $P$, Lindholm B, Jogestrand $T$, Heimburger $O$, et al.: Low fetuin-A levels are associated with cardiovascular death: Impact of variations in the gene encoding fetuin. Kidney Int 2005, 67(6):2383-2392.

23. Anderson MM, Requena JR, Crowley JR, Thorpe SR, Heinecke JW: The myeloperoxidase system of human phagocytes generates Nepsilon-(carboxymethyl)lysine on proteins: a mechanism for producing advanced glycation end products at sites of inflammation. J Clin Invest 1999, I04(I): I03-II3.

24. Baidoshvili A, Niessen HW, Stooker W, Huybregts RA, Hack CE, Rauwerda JA, Meijer CJ, Eijsman L, van Hinsbergh VW, Schalkwijk CG: N(omega)-(carboxymethyl)lysine depositions in human aortic heart valves: similarities with atherosclerotic blood vessels. Atherosclerosis 2004, I 74(2):287-292.

25. Ahmed MU, Brinkmann Frye E, Degenhardt TP, Thorpe SR, Baynes JW: $\mathbf{N}$-epsilon-(carboxyethyl)lysine, a product of the chemical modification of proteins by methylglyoxal, increases with age in human lens proteins. Biochem J 1997, 324(Pt 2):565-570.

26. Ahmed MU, Thorpe SR, Baynes JW: Identification of $\mathbf{N}$ epsiloncarboxymethyllysine as a degradation product of fructoselysine in glycated protein. J Biol Chem I 986, 26 I (I I):4889-4894.

27. Kaloudi O, Basta G, Perfetto F, Bartoli F, Del Rosso A, Miniati I, Conforti ML, Generini S, Guiducci S, Abbate R, et al.: Circulating levels of Nepsilon-(carboxymethyl)lysine are increased in systemic sclerosis. Rheumatology (Oxford) 2007, 46(3):4I2-4I6.

28. Ritthaler U, Deng Y, Zhang Y, Greten J, Abel M, Sido B, Allenberg J, Otto G, Roth $H$, Bierhaus $A$ : Expression of receptors for advanced glycation end products in peripheral occlusive vascular disease. Am J Pathol I995, I 46(3):688-694.

29. Kislinger T, Fu C, Huber B, Qu W, Taguchi A, Du Yan S, Hofmann M, Yan SF, Pischetsrieder M, Stern D, et al.: N(epsilon)-(carboxymethyl)lysine adducts of proteins are ligands for receptor for advanced glycation end products that activate cell signaling pathways and modulate gene expression. J Biol Chem 1999, 274(44):31740-3।749.

30. Schmidt AM, Yan SD, Yan SF, Stern DM: The multiligand receptor RAGE as a progression factor amplifying immune and inflammatory responses. J Clin Invest 2001, I 08(7):949-955.

31. Boutouyrie P, Bussy C, Lacolley P, Girerd X, Laloux B, Laurent S: Association between local pulse pressure, mean blood pressure, and large-artery remodeling. Circulation 1999 I 00(13): I387-1393.

32. Jondeau G, Boutouyrie P, Lacolley P, Laloux B, Dubourg O, Bourdarias JP, Laurent $S$ : Central pulse pressure is a major determinant of ascending aorta dilation in Marfan syndrome. Circulation 1999, 99(20):2677-268I.

33. Moser B, Szabolcs MJ, Ankersmit HJ, Lu Y, Ou W, Weinberg A Herold KC, Schmidt AM: Blockade of RAGE suppresses alloimmune reactions in vitro and delays allograft rejection in murine heart transplantation. Am J Transplant 2007, 7(2):293-302.

34. Tan KC, Shiu SW, Chow WS, Leng L, Bucala R, Betteridge DJ: Association between serum levels of soluble receptor for advanced glycation end products and circulating advanced glycation end products in type 2 diabetes. Diabetologia 2006 , 49( I I ):2756-2762.

35. Briet M, Bozec E, Laurent S, Fassot C, London GM, Jacquot C, Froissart $M$, Houillier $P$, Boutouyrie $P$ : Arterial stiffness and enlargement in mild-to-moderate chronic kidney disease. Kidney Int 2006, 69(2):350-357.

36. Mizutari K, Ono T, lkeda K, Kayashima K, Horiuchi S: Photoenhanced modification of human skin elastin in actinic elastosis by N(epsilon)-(carboxymethyl)lysine, one of the glycoxidation products of the Maillard reaction. The Journal of investigative dermatology 1997, I 08(5):797-802.

37. Bruel $\mathrm{A}$, Oxlund $\mathrm{H}$ : Changes in biomechanical properties, composition of collagen and elastin, and advanced glycation end- products of the rat aorta in relation to age. Atherosclerosis 1996 I 27(2): I55- 165 .

38. Boehm BO, Schilling S, Rosinger S, Lang GE, Lang GK, Kientsch-Engel $R$, Stahl P: Elevated serum levels of N(epsilon)-carboxymethyl-lysine, an advanced glycation end product, are associated with proliferative diabetic retinopathy and macular oedema. Diabetologia 2004, 47(8): |376-| 379.
Publish with Biomed Central and every scientist can read your work free of charge

"BioMed Central will be the most significant development for disseminating the results of biomedical research in our lifetime. "

Sir Paul Nurse, Cancer Research UK

Your research papers will be:

- available free of charge to the entire biomedical community

- peer reviewed and published immediately upon acceptance

- cited in PubMed and archived on PubMed Central

- yours - you keep the copyright 